\section{$\underset{\text { hommes }}{\text { \& migrations }}$}

\section{Hommes \& migrations}

Revue française de référence sur les dynamiques

migratoires

$1317-1318 \mid 2017$

L'Europe en mouvement

\title{
Nathacha Appanah, Tropique de la violence
}

Paris, Gallimard, 2016, 177 p., 17,50€.

\section{Mustapha Harzoune}

\section{(2) OpenEdition}

\section{Journals}

\section{Édition électronique}

URL : http://journals.openedition.org/hommesmigrations/3940

DOI : 10.4000/hommesmigrations.3940

ISSN : 2262-3353

\section{Éditeur}

Musée national de l'histoire de l'immigration

\section{Édition imprimée}

Date de publication : 1 avril 2017

Pagination : 197-198

ISBN : 978-2-919040-38-4

ISSN : $1142-852 X$

\section{Référence électronique}

Mustapha Harzoune, « Nathacha Appanah, Tropique de la violence», Hommes \& migrations [En ligne], 1317-1318 | 2017, mis en ligne le 01 avril 2017, consulté le 23 septembre 2020. URL : http:// journals.openedition.org/hommesmigrations/3940; DOI : https://doi.org/10.4000/ hommesmigrations.3940 
quoi s'aérer et faire reculer l'horizon. "Un livre peut te changer [...] il fautse méfier des livres, ce sont des génies endormis $\pi$.

Efficaces, les formules et les images frappent. Exemples, sur te métissage (" je tangue entre deux rives, mon âme a cette maladie-tz̀ ") ou le génocide (" le génocide est une marée noire, ceux qui ne s'y sont pas noyés sont mazoutés à vie »). Éloge aussi de ta littérature à propos de réfugiés et de teurs enfants: "Ĺopinion publique

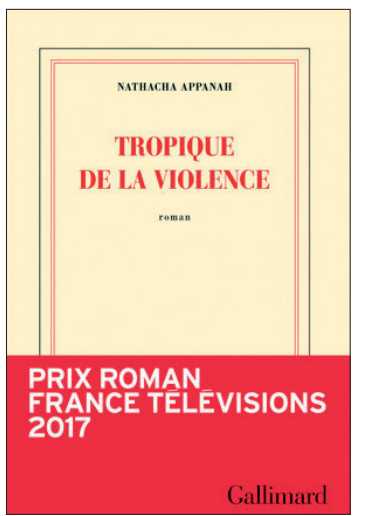

\section{Nathacha Appanah Tropique de la violence}

Paris, Gallimard, 2016, 177 p., $17,50 €$.

Âmes sensibles s'abstenir! Pourtant, ce Tropique de la violence se situe en France, dans l'enfer de Mayotte, à l'intersection de trois solitudes, trois façons de survivre. Marie est infirmière ; obsédée, dévorée, broyée, enlaidie - chaque année, chaque mois, un peu plus - par un désir inassouvi de maternité : "Quand vient le sang chaud dans ma culotte chaque mois, je pleure et je maudis toutes ces mères que je vois à l'hôpital qui ne connaissent rien à rien, toutes ces clandestines venues accoucher sur cette île française pour des papiers [...]. Je change, j'enfle mais il n'y a que de la mauvaise graisse en moi, ma tête pensera qu'ils ont fuil'enfer pour trouver l'Eldorado. Foutaises! On ne dira rien du pays encux. La poésie n'est pas de l'information. Pourtante'est la seute chose qu'un être humain retiendra de son passage sur terre. Je détourne tes yeux de ces images, eltes disent te réel, pas ta vérité. Ces enfants t'écriront peut-être, unjourn.

te récit s'ouvre sur te retour de Gabriet au Burundi. Ĺadulte qu'ilest devenu va faire la part du réetet de la vérité.

A.H.

tourne et mes paroles virent à l'aigre comme du lait. " Elle finit par enlever et adopter le bébé d'une clandestine. L'enfant a un œil noir et un œil vert. Pour sa mère, il est l'enfant du djinn. II porte malheur!

Moïse est le fils abandonné. À l'adolescence, il veut connaître son histoire. Tourmenté, il se détourne de celle qu'il n'appelle plus Mam mais Marie. « I/ me dit que je l'ai élevé comme un Blanc, que je l'ai empêché de vivre sa "vraie vie". " Le gamin rejoint ceux qu'il croit être les siens : les clandestins. II n'emporte qu'un livre, L'enfant et la rivière, et un sac à dos, celui de Marie, qui lui sert d'oreiller. « Quand j'ai su la vérité, je me suis senti un moins que rien, une merde, un gosse qui a fait peur à sa propre mère quand il est sorti d'elle, un gosse qu'elle a donné au premier venu, comment appeler cela?" Brutal et impitoyable, Bruce se revendique pur Mahorais, descendant d'esclaves, en rage contre la société. «Parce que tu crois que je suis né comme ça, 


\section{LIVRES}

moi, avec l'envie de taper, de mordre, de rentrer dedans » ? dit Ismaël Saïd, alias Bruce devenu le chef de Gaza, un ghetto à la lisière de Mamoudzou, " un immense camp de clandestins à ciel ouvert, c'est une énorme poubelle fumante que l'on voit de loin. Gaza c'est un no man's land violent où les bandes de gamins shootés au chimique font la loi. Gaza c'est Cape Town, c'est Calcutta, c'est Rio. Gaza c'est Mayotte, Gaza c'est la France. » Bruce déteste Moïse et ses « mots bien propres, bien ordonnés, des mots bien français, bien blancs ». II exècre les journalistes et autres "Blancs» qui viennent à Gaza comme ils vont au cinéma, avec de grands mots et de belles théories... D'ailleurs, malgré les enquêtes et les rapports, les promesses des politiciens véreux qui arrosent le bidonville le temps d'une élection, Mayotte est au bord de l'explosion. "Nous sommes seuls. " Seuls sur cette partie intégrante du territoire national où la violence est omniprésente : viol, exploitation sexuelle, rapports de domination, misère et avilissement des relégués, jusqu'à l'odeur du ghetto, jusqu'aux corps défigurés par la haine et les souffrances. Et, bien sûr, il y a les clandestins. En surnombre. Ceux qui ont échappé à la mort, entre Anjouan et Mayotte traînent « avec des cancers tellement avancés qu'ils n'existent plus, en métropole, que dans les livres de médecine. J'ai vu de grands brûlés à la peau toute pourrie, des bébés morts depuis plusieurs jours mais toujours dans les bras de leurs mères, des hommes aux jambes sectionnées par des requins ». Nathacha Appanah décrit l'insupportable sans porter de jugement. Cela tient au ton, mais aussi à l'exposition, de chapitre en chapitre, des angles (et non des points) de vue des trois protagonistes auxquels s'ajoutent les voix d'un policier et d'un éducateur. Elle réussit à provoquer cette disponibilité, non pas empathique, mais écoute, une sorte de tuishou (la poussée des mains au taî-chi) littéraire. Écouter, pour mieux sentir les logiques collectives à l'œuvre et comment chacun s'efforce de sortir la tête de l'eau, fusse pour une seule bouffée d'oxygène. Avant de transformer l'innocent en assassin. M. H.

reconnaitre, dire et redire que ces auteurs sont les sismographes des temps modernes, les géologues attentifs de ta tectonique des peuples, les cartographes des nouvelles appartenances et des nouveaux imaginaires. Its rincent le coeuretl'âme des biles de " fautofiction névrotique parisienne $\pi$ (dixit Andrei Makine, discours de réception à l'Académie française). Les uns ouvrent, les autres (en)ferment. 